\title{
Anxiety disorders and stressful events in Takotsubo syndrome
}

\author{
Davide Lazzeroni ${ }^{1}$, Matteo Bini ${ }^{2}$, Paolo Castiglioni ${ }^{1}$, Luca Moderato ${ }^{2}$, \\ Chiara Ciraci ${ }^{3}$, Umberto Camaiora ${ }^{3}$, Pietro Tito Ugolotti ${ }^{3}$, Lorenzo Brambilla ${ }^{1}$, \\ Valerio Brambilla ${ }^{3}$, Silvia Garibaldi ${ }^{3}$, Letizia Paglialonga ${ }^{3}$, Valentina Ziveri ${ }^{3}$, \\ Fabrizio Ugo ${ }^{4}$, Nicola Gaibazzi ${ }^{5}$, Paolo Coruzzi ${ }^{2}$ \\ ${ }^{1}$ IRCCS Fondazione Don C. Gnocchi, Milan, Italy \\ ${ }^{2}$ Department of Clinical and Experimental Medicine, University of Parma, Italy \\ ${ }^{3}$ Cardiovascular Prevention and Rehabilitation Unit, Don Carlo Gnocchi Foundation, Parma, Italy \\ ${ }^{4}$ Division of Cardiology, San Giovanni Bosco Hospital, Turin, Italy \\ ${ }^{5}$ Department of Cardiology, Parma University Hospital, Parma, Italy
}

\begin{abstract}
Background: Anxiety disorders are more common in Takotsubo syndrome (TS) than in acute coronary syndrome patients. The aim of this study was to investigate whether pre-existing anxiety disorders predispose to TS triggered by exclusively emotional stressful events.

Methods: Triggering events were compared in 58 TS patients with and without pre-existing anxiety disorders; clinical, electrocardiographic and echocardiographic data were also collected.

Results: Thirty-one (53\%) patients had a previous history of anxiety disorders. The exclusively emotional stressful event-rate was higher in TS patients with pre-existing anxiety disorder (74\% vs. 30\%, $p=0.001$ ), while TS caused by an undetermined trigger were significantly higher in patients without anxiety disorders (33\% vs. $10 \%, p=0.027)$. Moreover, in TS patients without a previous history of anxiety disorders, a trend of higher prevalence of physical events was found (16\% vs. $37 \%, p=0.07)$. Conclusions: In patients with pre-existing anxiety disorders, TS was predominantly triggered by exclusively emotional stressful events, thereby suggesting a possible relationship between anxiety and emotional cardiac frailty in TS patients. (Cardiol J 2018; 25, 4: 495-500)
\end{abstract}

Key words: Takotsubo syndrome, anxiety disorders, stressful events, stress cardiomyopathy, psychiatric disorders

\section{Introduction}

Takotsubo syndrome (TS) is an acute stressinduced cardiomyopathy mimicking myocardial infarction (MI) in the absence of obstructive coronary artery disease [1]. Takotsubo is characterized by a transient ventricular dysfunction, usually reversible in few days, although some long-lasting clinical consequences can be identified after the acute phase [2]. Even though previous studies have suggested that TS is predominantly preceded by exclusively emotional trigger events [3, 4], the disease may also occur with physical trigger events or even without any evident preceding stressful trigger [3]. Physically triggered TS seems to be associated with reduced cardiovascular reserve [5], high in-hospital mortality rate [6] and adverse long-term outcomes [7].

Recently, the international Takotsubo registry revealed that more than half of patients with TS had preceding neurologic or psychiatric disorder [7]. Among the psychiatric disorders related to TS,

Address for correspondence: Dr. Luca Moderato, Department of Clinical and Experimental Medicine, University of Parma, Italy, tel: 00390521 2054, e-mail: moderatoluca@gmail.com 
anxiety is one of the more frequent [8]. Psychosocial and psychiatric risk factors are frequently involved in the pathogenesis of most common cardiac diseases, such as coronary heart disease or acute coronary syndrome (ACS) [9], and might also have a role in predisposing to TS [8]. Anxiety disorder seems to be more common in TS patients than in patients with ACS [7] or in the general hospitalized population without cardiac disease [10].

Under investigation in this study was whether a relationship exists between chronic or former anxiety disorders and primary TS triggered by exclusively emotional stressful events; this was done by comparing the type of stressful events in TS patients with or without a history of anxiety disorder.

\section{Methods}

Sixty one TS patients were retrospectively analyzed and were consecutively admitted to the Cardiovascular Unit (Cardiology Department, Parma University Hospital) from 2008 to 2011.

Takotsubo syndrome was defined by following the Mayo Clinic diagnostic criteria for this condition, as follows: "the presence of a transient abnormality in left ventricular wall motion beyond a single epicardial coronary artery perfusion territory, the absence of obstructive coronary artery disease or angiographic evidence of acute plaque rupture, the presence of new electrocardiographic abnormalities or elevation in cardiac troponin levels, and the absence of pheochromocytoma and myocarditis. Exceptions to these criteria were the presence of coexisting coronary artery disease, the presence of a wall-motion abnormality that was congruent with a single coronary artery territory in a patient matching all other criteria, and death during the acute phase before wall motion recovery" [7].

All patients underwent coronary angiography.

Similar to other retrospective studies, anxiety disorders were evaluated from medical records data, pre-existing psychiatric diagnosis and/or chronic use of benzodiazepines [10]. Among these patients, $10 \%$ had a specific diagnosis of anxiety disorder without information regarding the chronic use of benzodiazepines (BZD), while in 3 patients chronic use of BDZ was found in medical records without a specific pre-existing psychiatric diagnosis. Finally, 3 patients, 2 with chronic depression and 1 with bipolar disorder, were excluded in the present study as potential confounders. Considering the presence or absence of pre-existing anxiety disorders, the remaining 58 TS subjects were divided into two groups, and stressful events
Table 1. Stressful events triggering Takotsubo syndrome.

\begin{tabular}{|c|c|}
\hline Type of stressful event/Description & $\mathbf{N}$ \\
\hline \multicolumn{2}{|l|}{ Emotional stressful event } \\
\hline \multicolumn{2}{|l|}{ Grief/loss: } \\
\hline Death of a friend & 1 \\
\hline $\begin{array}{l}\text { Death of a relative when son was } \\
\text { far away from home }\end{array}$ & 1 \\
\hline Death of the spouse & 2 \\
\hline $\begin{array}{l}\text { Death of the spouse and financial } \\
\text { problems }\end{array}$ & 1 \\
\hline Grief/loss in the family (no more detail) & 2 \\
\hline Total & 7 \\
\hline \multicolumn{2}{|l|}{ Panic/fear: } \\
\hline Anxiety for university exam of the son & 1 \\
\hline $\begin{array}{l}\text { Fear of cancer in patient with recent } \\
\text { loss of weight }\end{array}$ & 2 \\
\hline $\begin{array}{l}\text { Fear of cancer while waiting for } \\
\text { endoscopic exams }\end{array}$ & 2 \\
\hline Fear for the fall of handicapped son & 2 \\
\hline $\begin{array}{l}\text { Fear for recent diagnosis of Alzheimer's } \\
\text { disease of the husband }\end{array}$ & 1 \\
\hline $\begin{array}{l}\text { Fear for recent diagnosis of arterial } \\
\text { hypertension }\end{array}$ & 1 \\
\hline Fear for a grandchild disease & 1 \\
\hline Fear for aortic dissection of the spouse & 1 \\
\hline Total & 11 \\
\hline \multicolumn{2}{|l|}{ Interpersonal conflict: } \\
\hline Argument with the son far away from home & 1 \\
\hline Argument with employer & 2 \\
\hline Argument with the spouse & 2 \\
\hline Divorce of the son & 1 \\
\hline Argument (no more detail) & 2 \\
\hline Argument with a student (professor) & 1 \\
\hline Argument with the son for residency permit & 1 \\
\hline \multicolumn{2}{|l|}{ Other: } \\
\hline $\begin{array}{l}\text { Other emotional stressful event } \\
\text { (no more detail) }\end{array}$ & 3 \\
\hline Total & 13 \\
\hline \multicolumn{2}{|l|}{ Physical stressful event } \\
\hline \multicolumn{2}{|l|}{ Gastro-intestinal diseases: } \\
\hline Acute cholecystitis & 1 \\
\hline Bleeding peptic ulcer & 1 \\
\hline \multicolumn{2}{|l|}{ Surgery: } \\
\hline Thyroidectomy & 2 \\
\hline Oncological palliative sugery & 1 \\
\hline \multicolumn{2}{|l|}{ Neurological diseases: } \\
\hline Seizure & 3 \\
\hline \multicolumn{2}{|l|}{ Traumatic disorders: } \\
\hline Car crash & 1 \\
\hline Traumatic fall & 5 \\
\hline \multicolumn{2}{|l|}{ Other: } \\
\hline Hemodialysis session & 1 \\
\hline Total & 15 \\
\hline
\end{tabular}


were further classified in exclusively emotional, undetermined and physical (Table 1). The stressful event was considered a trigger when it occurred within $12 \mathrm{~h}$ before clinical presentation. Undetermined stressful events were defined when anamnestic evaluation failed to identify any possible specific trigger.

Other anamnestical, clinical, laboratory, electrocardiographic and echocardiographic data were collected at discharge. Approval was obtained from the documented ethical committee on human research and the patients gave their written informed consent.

\section{Statistical analysis}

Differences in the distribution of stressful events between TS patients with or without anxiety disorders were evaluated by the Pearson $\chi^{2}$ test. Differences between groups with and without anxiety disorders were evaluated by $\chi^{2}$ test for categorical variables and by unpaired Student $t$ test for continuous variables, with statistical significance at 5\% (IBM SPSS Statistics 22.0 Armonk, NY).

\section{Results}

Among the present group of 58 TS patients (mean age 70 years, female gender $97 \%$ ), preexisting anxiety disorders was found in 31 patients. According to the type of TS, 65\% (38 patients) showed apical ballooning, 23\% (13 patients) mid ventricular ballooning and $12 \%$ (7 patients) basal/inverted ballooning. No significant coronary stenosis or thrombosis was found, except for 1 patient with $70 \%$ stenosis of first diagonal branch (evaluated as non-culprit lesion not able to justify left ventricular dysfunction); moreover in 18 (31\%) patients a mild/subclinical (less than $40 \%$ ) stenosis was found.

Exclusively emotional stressful events were identified in $53 \%$ and physical stressful events in $26 \%$ of patients, respectively; the remaining 12 (21\%) patients developed TS without a specific identifiable trigger (undetermined stressful event). Distributions of emotional, physical or undetermined TS triggering stressful events differed markedly between the groups with and without a history of anxiety disorders. In particular, exclusively emotional stressful events were more common in TS patients with pre-existing anxiety disorder ( $74 \%$ vs. $30 \%, p=0.001$; Fig. 1 ). In contrast TS patients without a history of anxiety disorders undetermined stressful events were more common $(10 \%$ vs. $33 \%, p=0.027)$, and physical-type

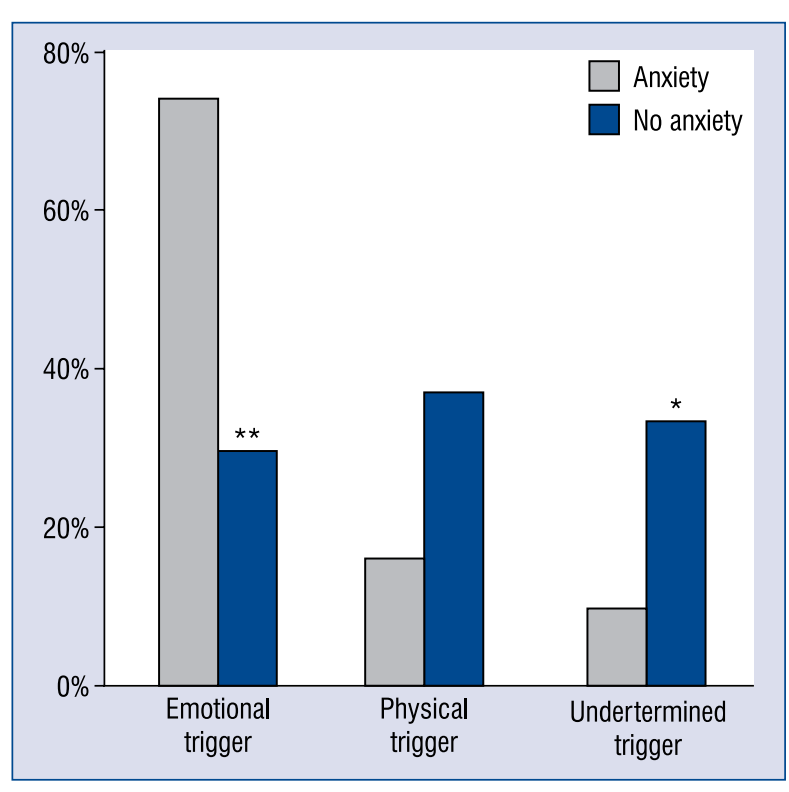

Figure 1. Frequency of emotional, physical and undetermined stressful events in Takotsubo syndrome patients with versus without pre-existing anxiety disorders. The * and ${ }^{* *}$ symbols indicate differences between the two groups significant at $p<0.05$ and $p<0.01$ significance level.

triggers tended to have higher prevalence ( $16 \%$ vs. $37 \%, \mathrm{p}=0.07)$. No significant differences between groups were also found in age, gender, cardiovascular risk factors, clinical presentation, medical therapy, electrocardiographic data. Moreover, no differences were found between groups in left ventricular function at admission, at discharge and after 1 month from discharge (Table 2).

\section{Discussion}

The present data represents the first evidence of an association between pre-existing anxiety disorders and TS triggered by an exclusively emotional stressful event. In particular, a much higher prevalence was found with exclusively emotional stressful events in TS patients with pre-existing anxiety disorders compared with patients without anxiety. Moreover, except for a stressful event, no significant differences in clinical, laboratory, electrocardiographic and echocardiographic data were found between TS patients with or without pre-existing anxiety disorders.

Even though psychiatric disorders are more common in TS subjects than in ACS patients [7], according to available research the possible relationship between pre-existing anxiety disease and type of TS triggering event has never been 
Table 2. Baseline characteristics of Takotsubo syndrome (TS) patients with and without anxiety disorder.

\begin{tabular}{|c|c|c|c|}
\hline Variables & TS with anxiety & TS without anxiety & $\mathbf{P}$ \\
\hline Age [years] & $72 \pm 8$ & $68 \pm 12$ & 0.121 \\
\hline Female gender & $30(97 \%)$ & $26(96 \%)$ & 0.921 \\
\hline Body mass index & $24 \pm 4$ & $24 \pm 3$ & 0.607 \\
\hline \multicolumn{4}{|c|}{ Cardiovascular risk factors } \\
\hline Arterial hypertension & $25(81 \%)$ & $23(85 \%)$ & 0.648 \\
\hline Dyslipidemia & $18(58 \%)$ & $14(52 \%)$ & 0.635 \\
\hline Diabetes & $4(13 \%)$ & $3(11 \%)$ & 0.834 \\
\hline Smokers & $3(10 \%)$ & $4(15 \%)$ & 0.549 \\
\hline \multicolumn{4}{|l|}{ Clinical features } \\
\hline Angina & $28(97 \%)$ & $23(88 \%)$ & 0.249 \\
\hline Dyspnoea & $7(24 \%)$ & $11(41 \%)$ & 0.184 \\
\hline \multicolumn{4}{|l|}{ Electrocardiography } \\
\hline STEMI & $8(27 \%)$ & $8(30 \%)$ & 0.866 \\
\hline NSTEMI & $21(72 \%)$ & $18(67 \%)$ & 0.640 \\
\hline Giant T wave & $16(52 \%)$ & $20(74 \%)$ & 0.140 \\
\hline QTc & $467(70 \%)$ & $528(16 \%)$ & 0.159 \\
\hline \multicolumn{4}{|c|}{ Echocardiographic measures } \\
\hline LVEF at admission [\%] & $39 \pm 5$ & $38 \pm 6$ & 0.729 \\
\hline \multicolumn{4}{|l|}{ Laboratory data } \\
\hline Troponin peak [ng/dL] & $2.4 \pm 2.5$ & $3.2 \pm 3.0$ & 0.356 \\
\hline \multicolumn{4}{|l|}{ Drugs } \\
\hline ASA & $25(83 \%)$ & $22(85 \%)$ & 0.896 \\
\hline Beta-blockers & $25(81 \%)$ & $21(78 \%)$ & 0.788 \\
\hline Statin & $9(30 \%)$ & $8(31 \%)$ & 0.950 \\
\hline RAAS-i & $19(63 \%)$ & $19(73 \%)$ & 0.436 \\
\hline
\end{tabular}

STEMI - ST-segment elevation myocardial infarction; NSTEMI — non-ST-segment elevation myocardial infarction; LVEF — left ventricular ejection fraction; ASA — acetylsalicylic acid; RAAS-I — renin-angiotensin system inhibitors

established. Data from the International Takotsubo Registry [7] showed a significantly higher prevalence of psychiatric disorders and chronic neurological diseases in TS subjects than in age- and sex-matched patients with ACS, strengthening the hypothesized association between neuropsychiatric disorders and TS. Since anxiety is one of the more common psychiatric disorders in TS, ranging between $21 \%$ and $56 \%[10,11]$, the present results confirm the high prevalence of anxiety disorders in TS and suggest a relationship between underlying anxiety and an exclusively emotional stressful trigger.

An association between psychosocial factors and TS, most likely mediated by neurophysiological pathways, has been recently suggested [8]. More specifically, patients with anxiety disorders display an enhanced sympathetic response to physical or emotional stressors as well as a reduced parasympathetic activity expressed as abnormal heart rate variability and recovery [12-14]. An impairment of sympatho-vagal balance has also been demonstrated during both acute [4] and quiescent phase of TS, thereby supporting the hypothesis of a neurogenic-mediated myocardial stunning due to autonomic dysfunction (Fig. 2) [15-17]. Data herein linking emotional stressor, anxiety and TS suggests the utility of further studies aimed to evaluate the relationship between autonomic dysfunction, neuropsychiatric disorders and emotional frailty in TS patients.

Limitations that should be considered are the retrospective design of the study and the lack of pre-existing psychiatric tests allowing to a specific distinction between trait or state of anxiety.

\section{Conclusions}

Takotsubo syndrome appears predominantly triggered by exclusively emotional stressful events 


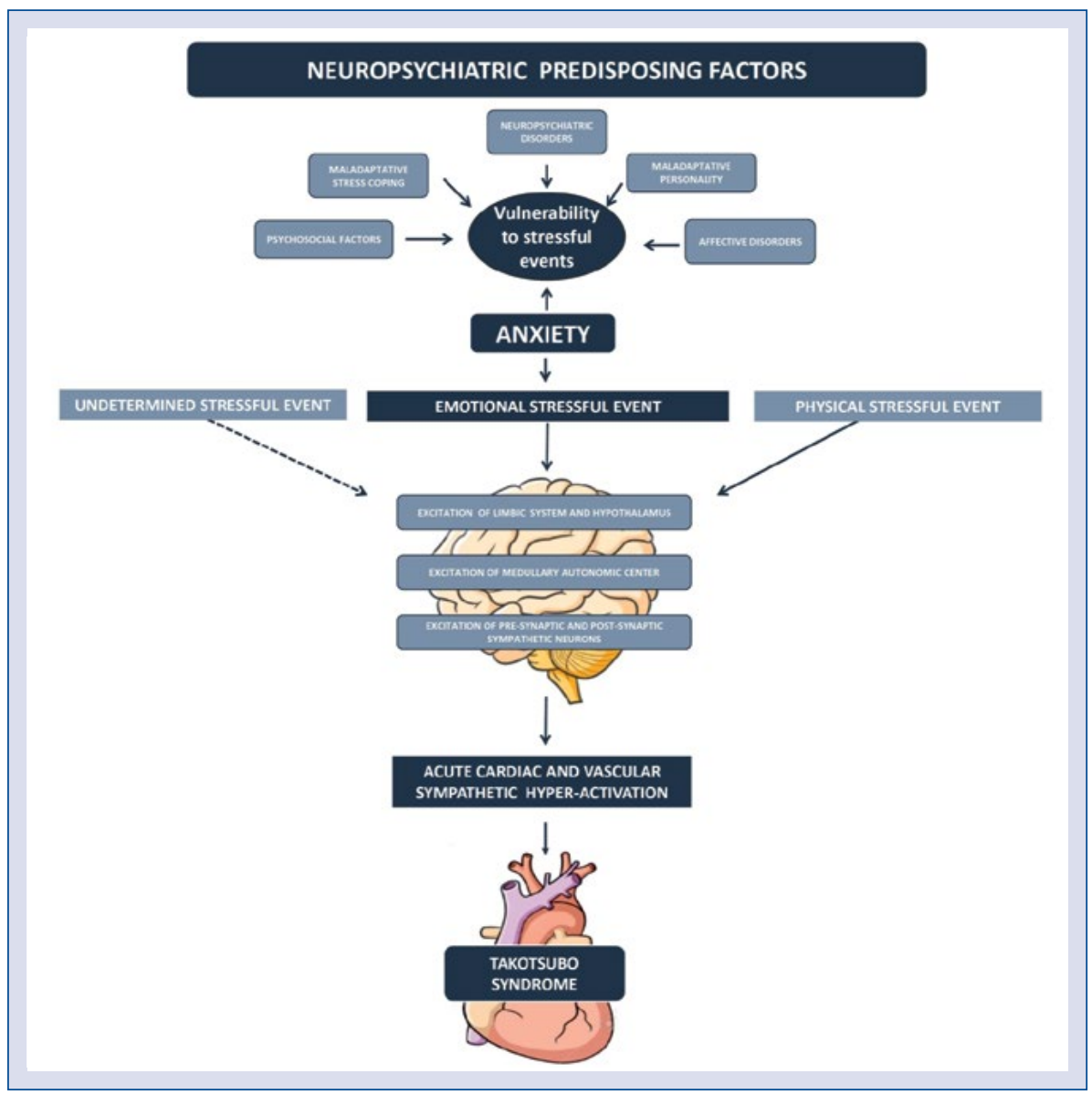

Figure 2. Role of anxiety in predisposing Takotsubo syndrome (TS). Relationship between neuropsychiatric factors and enhanced sympathetic response to emotional stressful events in TS.

in patients with pre-existing anxiety disorders, suggesting a possible relationship between anxiety and emotional cardiac frailty in TS patients.

\section{Conflict of interest: None declared}

\section{References}

1. Prasad A, Lerman A, Rihal CS. Apical ballooning syndrome (Tako-Tsubo or stress cardiomyopathy): a mimic of acute myocardial infarction. Am Heart J. 2008; 155(3): 408-417, doi: 10.1016/j. ahj.2007.11.008, indexed in Pubmed: 18294473.

2. Nowak R, Fijalkowska M, Gilis-Malinowska N, et al. Left ventricular function after takotsubo is not fully recovered in long-term follow-up: A speckle tracking echocardiography study. Cardiol J. 2017; 24(1): 57-64, doi: 10.5603/CJ.a2017.0001, indexed in Pubmed: 28070881.

3. Lyon AR, Bossone E, Schneider B, et al. Current state of knowledge on Takotsubo syndrome: a Position Statement from the Taskforce on Takotsubo Syndrome of the Heart Failure Association of the European Society of Cardiology. Eur J Heart Fail. 2016; 18(1): 8-27, doi: 10.1002/ejhf.424, indexed in Pubmed: 26548803 .
4. Wittstein IS, Thiemann DR, Lima JAC, et al. Neurohumoral features of myocardial stunning due to sudden emotional stress. NEnglJ Med. 2005;352(6):539-548, doi: 10.1056/NEJMoa043046, indexed in Pubmed: 15703419.

5. Song BG, Yang HS, Hwang HK, et al. The impact of stressor patterns on clinical features in patients with tako-tsubo cardiomyopathy: experiences of two tertiary cardiovascular centers. Clin Cardiol. 2012; 35(11): E6-13, doi: 10.1002/clc.22053, indexed in Pubmed: 23027688.

6. Sobue $\mathrm{Y}$, Watanabe E, Ichikawa T, et al. Physically triggered Takotsubo cardiomyopathy has a higher in-hospital mortality rate. Int J Cardiol. 2017; 235: 87-93, doi: 10.1016/j.ijcard.2017.02.090, indexed in Pubmed: 28262347.

7. Templin C, Ghadri JR, Diekmann J, et al. Clinical Features and Outcomes of Takotsubo (Stress) Cardiomyopathy. N Engl J Med. 2015; 373(10): 929-938, doi: 10.1056/NEJMoa1406761, indexed in Pubmed: 26332547.

8. Rosengren A, Hawken S, Ounpuu S, et al. Association of psychosocial risk factors with risk of acute myocardial infarction in 11119 cases and 13648 controls from 52 countries (the INTERHEART study): case-control study. Lancet. 2004; 364(9438): 953-962, doi: 10.1016/ S0140-6736(04)17019-0, indexed in Pubmed: 15364186.

9. Kastaun S, Gerriets T, Tschernatsch M, et al. Psychosocial and psychoneuroendocrinal aspects of Takotsubo syndrome. Nat Rev 
Cardiology Journal 2018, Vol. 25, No. 4

Cardiol. 2016; 13(11): 688-694, doi: 10.1038/nrcardio.2016.108, indexed in Pubmed: 27411402.

10. Summers MR, Lennon RJ, Prasad A. Pre-morbid psychiatric and cardiovascular diseases in apical ballooning syndrome (takotsubo/stress-induced cardiomyopathy): potential pre-disposing factors? J Am Coll Cardiol. 2010; 55(7): 700-701, doi: 10.1016/j. jacc.2009.10.031, indexed in Pubmed: 20170799.

11. Ugo A, et al. Psychiatric disorders in takotsubo cardiomyopathy compared with acute coronary syndrome patients. Int J Cardiovasc Res. 2016; 5(6), doi: 10.4172/2324-8602.1000292.

12. Hemingway H, Malik M, Marmot M. Social and psychosocial influences on sudden cardiac death, ventricular arrhythmia and cardiac autonomic function. Eur Heart J. 2001; 22(13): 1082-1101, doi: 10.1053/euhj.2000.2534, indexed in Pubmed: 11428849.

13. Sanchez-Gonzalez MA, Guzik P, May RW, et al. Trait anxiety mimics age-related cardiovascular autonomic modulation in young adults. J Hum Hypertens. 2015; 29(4): 274-280, doi: 10.1038/jhh.2014.72, indexed in Pubmed: 25355009.
14. Friedman BH. An autonomic flexibility-neurovisceral integration model of anxiety and cardiac vagal tone. Biol Psychol. 2007; 74(2): 185-199, doi: 10.1016/j.biopsycho.2005.08.009, indexed in Pubmed: 17069959.

15. Smeijers L, Szabó BM, van Dammen L, et al. Emotional, neurohormonal, and hemodynamic responses to mental stress in Tako-Tsubo cardiomyopathy. Am J Cardiol. 2015; 115(11): 1580-1586, doi: 10.1016/j.amjcard.2015.02.064, indexed in Pubmed: 25910524.

16. Lazzeroni D, Bini M, Castiglioni P, et al. Autonomic function in Takotsubo syndrome long after the acute phase. Int J Cardiol. 2017; 231: 222-224, doi: 10.1016/j.ijcard.2017.01.002, indexed in Pubmed: 28089152.

17. Norcliffe-Kaufmann L, Kaufmann H, Martinez J, et al. Autonomic Findings in Takotsubo Cardiomyopathy. Am J Cardiol. 2016; 117(2): 206-213, doi: 10.1016/j.amjcard.2015.10.028, indexed in Pubmed: 26743349. 